\title{
Cultural intelligence of chemical engineering students: A demographics study
}

\author{
D. Beneroso ${ }^{\text {* }}$, N. Alosaimi ${ }^{\mathrm{b}}$
}

${ }^{a}$ Department of Chemical and Environmental Engineering, Faculty of Engineering, The University of Nottingham - Nottingham, United Kingdom

${ }^{\mathrm{b}}$ Department of Clinical Pharmacy, King Saud University - Riyadh, Saudi Arabia

* Corresponding Author's Email: daniel.benerosovallejo@nottingham.ac.uk

\begin{abstract}
An empirical investigation into the influence of demographic characteristics as foundations of cultural intelligence of chemical engineering students is addressed for the first time in this study. Following a validated cultural intelligence methodology, 108 UK final-year BEng students responded to questions spanning the four dimensions of cultural intelligence: metacognitive, cognitive, motivational and behavioural cultural intelligences. Overseas students reported a wider understanding of cross-cultural situations (cognitive intelligence), whereas UK students were more confident of their capabilities to perform and adjust themselves in cross-cultural scenarios (motivational intelligence). Ethnicity also played a key role; Asian students showed the highest cognitive cultural intelligence but also the lowest motivational intelligence, whereas black minority ethnic (BME) students reported the highest motivational cultural intelligence.

A fundamental understanding of the relationships between demographic characteristics and the four dimensions of cultural intelligence is needed to drive the transition towards a more global engineering educational strategy, where students can receive an enhanced support to efficiently deal with decision making, adaptive and task performance and adjustment in cross-cultural academic environments.
\end{abstract}

\section{Keywords}

Cultural Intelligence, CQ, Diversity, BAME, Engineering Education, Global Engineering 


\section{Introduction}

The key innovations that will shape the future of the global engineering education sector are unlikely to be new teaching methodologies or curricula components, but rather the underpinning institutional strategies behind how programmes are managed, structured and delivered in practice (Graham (2018)). In this regard, supporting the development of global outlook and experiences across the learning community has become a crucial driver for leading engineering institutions to ultimately help undergraduate and postgraduate students in developing professional engineering skills to operate more effectively in global, cross-cultural working environments.

Drawing from the foundations of the cultural capital concept, a construct that comprises the range of attributes, values and habits, transmitted by the family that influence an individual's educational achievements (Bourdieu (1986)), Ng, Tan et al. (2011) argued that organisations possessing what they called global culture capital could equally provide a work environment able to foster the development of human capital, defined as the education, experience, and skills of their employees, through the process of situated learning; i.e., through exposure to authentic contextualised activities as a source of learning acquisition (Brown, Collins et al. (1989)). Ng, Tan et al. (2011) proposed two elements underpinning the global culture capital framework of organisations, namely organisational values and routines; organisational values being described as the intangible cultural elements that embrace a global mindset, whereas organisational routines being represented by the operational procedures aiming at promoting such global values and mindset. These two elements were stated to create opportunities for continued enhancement of cultural processing skills and authentic cross-cultural interactions for employees across geographical locations and hence, to develop their ability for successful adaptation to new cultural settings

Scaling up such values and routines within the scope of higher education institutions and their programmes to efficiently build a global culture capital is not a minor task; for instance, Etzkowitz, Kemelgor et al. (2000) discussed how cultural shifts in the management of departments can bring about a gender equality mindset through sustainment of a collegial atmosphere that provides the safety for taking risks to conduct innovative work and expand collaborative networks. Stolle-McAllister (2011) explored how a pre-university bridge course could effectively help highly talented underrepresented science, technology, engineering and mathematics (STEM) students to navigate a wider cultural and social sphere by early learning 
of accepted modes of professional conduct and norms and the sense of belonging to a social network that promotes such norms. Rodriguez-Falcon, Hodzic et al. (2011) proposed an interactive and student-centred pedagogical tool to help engineering management students to recognise and value their cultural capital as a means of enhancing their cross-cultural knowledge and skills. The authors suggested this tool could help academics to realise student cohorts are a highly diverse community who identify each other through diverse value structures.

Even though these studies encourage either the development of global culture capital or students' cultural capital, academics and managers within schools may lack both the experience and the training in many occasions to consistently deal with shaping programmes to target the enhancement of students' cultural processing skills and their desire to engage with the full spectrum of cultural, social and political considerations that emerge when working on global tasks (Lucena and Schneider (2008), Jesiek (2013)). Indeed, research on human factors informing practice development of professional skills has been mostly focused on singleintelligence dimensions such as logical-mathematical, linguistic and spatial intelligence, whilst newer intelligence dimensions related to self-regulation, interpersonal social skills or cultural awareness aimed at enhancing the cultural capital of students have been less explored (Brualdi Timmins (1996)). In this regard, the cultural intelligence (CQ) construct - underpinned by a person's competence to function and manage effectively culturally diverse circumstances and settings (Earley (2002))- has been reported to be a framework that comprehensively embody the operationalisation of human capital in an organisation ( $\mathrm{Ng}$, Tan et al. (2011)), which can assist in predicting a set of culturally-diverse work outcomes such as decision making, performance and adjustment (Ang, Van Dyne et al. (2007)). For instance, in their systematic review, Solomon and Steyn (2017) concluded how competencies such as intercultural sensitivity and team adaptive performance, cross-cultural adjustment, or even international leadership potential were significantly related to high CQ levels. Drawing from this last study, an understanding about the CQ of students has therefore the potential to assist education practitioners and managers to make a transition towards a more holistic, global engineering education strategy (Cranmer (2006), Tymon (2013), Lin and Shen (2019)).

Having reviewed a high number of conceptual and empirical articles published on CQ, Ott and Michailova (2018), concluded that CQ research is now leaving its infancy stage and highlighted that cultural intelligence is beyond a single cognitive intelligence dimension (usually measured by IQ). Although several models can be found to describe the CQ concept (Bennett (1986), 
King and Baxter Magolda (2005)), all of them share a framework where individuals undergo multiple dimensions of development that combine together to describe a larger construct, allowing individuals the possibility to develop along dimensions at different rates. In addition to a cognitive dimension, CQ encompasses three other dimensions namely behavioural, motivational and metacognitive dimensions (Earley and Ang (2003)), that integrate and conceptualise different individual-level perspectives of intelligences. Metacognitive CQ reflects the ability of a student to think about prevailing cross-cultural exchanges, whereas cognitive CQ refers to the knowledge students have about different cultures. Motivational CQ evidences the desire of students to immerse in other cultures and the willingness to use their emotional energy in transitioning to cultural settings that they may not be used to. Finally, behavioural CQ is the student's ability to act and react appropriately during cross-cultural exchanges. All these four dimensions change over time based on people's experiences, efforts, contexts and interactions, and academic training and experiential learning interventions based on the situated learning framework have been shown to stimulate individuals' cultural intelligence (MacNab (2012), Eisenberg, Lee et al. (2013), Wood and St. Peters (2014)).

Van Dyne, Ang et al. (2015) examined the construct validity of CQ through six different casestudies involving $>1500$ undergraduate students. The authors found such construct to be stable across samples of students, time and across countries; hence, providing strong evidence of its robustness. Regarding specific CQ dimensions, the metacognitive and cognitive intelligence dimensions were found to significantly increase cultural judgement and decision making, whereas the behavioural and motivational intelligence dimensions consistently increased personal adjustment and mental wellbeing in cross-cultural settings. As a result, the authors recommend to use CQ as a valuable tool to provide feedback and self-awareness to individuals in order to aid them to improve their cross-cultural effectiveness (Paige and Martin (1996)). Shannon and Begley (2008) hypothesised that language acquisition, international working experience and diversity of social contact should positively relate to increased CQ levels and inferred that language acquisition only fostered the cognitive intelligence dimension; international work experiences had a positive effect upon the motivational intelligence dimension, and that the diversity of participants' social contacts (e.g., parents' birthplaces or countries where participants had attended university) was unrelated to any cultural intelligence dimension. Moreover, this study pioneered the investigation into the relationship between selfrated and peer-rated CQ; a significant positive relationship being inferred from the collected data and suggesting a mechanism to predict outcomes in cross-cultural work scenarios. Crowne 
analysed the relationship between cultural exposure and cultural intelligence; particularly the positive influence of cultural exposure both in terms of depth (i.e., reasons why individuals were abroad; e.g. work, education, holidays, missionary work, etc.) and breadth (i.e., number of countries visited abroad) on cultural intelligence (Crowne (2008), Crowne (2013)). Only the number of countries visited for education and work were found to have a significant influence on a person's level of cultural intelligence. Likewise, Alosaimi, Boyd et al. (2019) studied the cultural intelligence of a cohort of MPharm undergraduate students and found out that students who had lived abroad reported to behave more effectively in cross-cultural situations. Báez (2013) explored how gender could have an effect on an individual's CQ and found out that the females enrolled in her study showed a significantly higher motivational cultural intelligence, this being attributed to diverse biological and sociological factors (Kitchenham (2002)). Khodadady and Ghahari (2011) reported that females also exhibited a significantly higher metacognitive cultural intelligence in the context of Iranian higher education. However, following Bryman (2016), it is important to bear in mind that the inferred claims from these social studies are grounded on association between variables, which are not strictly of a causal nature since other contextual factors, such as social and cultural values and norms, affect the measured construct (Bhaskar (2013)).

Despite the significant contribution of existing research studies on CQ antecedents, characterisation and outcomes in cross-cultural situations, the great majority of such literature is limited to the context of business courses and work environments (Van Dyne, Ang et al. (2010)). Goh (2012) highlighted the growing potential of cultural intelligence and its applications across several education subjects, and discussed examples of ways to implement the CQ construct into existing curricula but the offered discussion is mainly theoretical, missing any quantitative empirical evidence. Perhaps, the major finding from this study is the lack of a one-size-fits-all methodology to develop an integrated cross-cultural education. Al-Momani and Atoum (2016) did however not find statistical differences in any of the cultural intelligence dimensions due to the nature of the undergraduate students' subject (i.e., STEM vs humanitiesbased programmes) in the context of Jordanian universities.

In the particular case of the engineering education literature, Mazzurco, Jesiek et al. (2012) examined the cultural intelligence dimensions among undergraduates engineering students from five different programmes at the Worcester Polytechnic Institute and Purdue University. Most of these programmes included an element -either a learning community, professional seminars or international experiences- aimed at improving their students' global competence 
where cross-culturalism features were included, which therefore was manifested in terms of higher CQ levels. Del Vitto (2008) and Gash, Ressler et al. (2009) emphasised the importance of CQ with regards to the global, cross-cultural skills of engineers but none did report any empirical or statistically significant findings.

To the best of the authors' knowledge, the use of CQ across engineering education studies and indeed, across the STEM education literature- is extremely limited, and thus a potential tool for understanding how to enhance students' cultural capital to effectively work in global environments remains unexploited (Davis and Knight (2018)). Herein, we report for the first time a complete characterisation and analysis of the cultural intelligence of a large, diverse final-year BEng Chemical Engineering cohort by means of a validated cultural intelligence scale protocol (CQS) to assess the following research question: What are the most significant demographic characteristics that correlate with the level of cultural intelligence of undergraduate chemical engineering students?

\section{Materials and Methods}

To address the above research question, a large cohort of students was surveyed following a validated cultural intelligence protocol (CQS). Descriptive and inferential statistics were used to characterise the cultural intelligence dimensions of the students and to determine whether some of demographic characteristics were statistically significant in inferring any of the level of cultural intelligence dimensions.

\subsection{Participants}

Data for this study were collected from a cohort of 140 final-year BEng Chemical and Environmental Engineering students at the University of Nottingham (UK). 108 students (i.e., $77 \%$ response rate) agreed to take part in this study and the demographic characteristics of the analysed cohort are summarised in Table $\mathbf{1 .}$

Table 1 Demographic characteristics of the sample group.

\begin{tabular}{|l|l|c|c|}
\hline Category & Subcategory & $\begin{array}{c}\text { Number of } \\
\text { students }\end{array}$ & \% of students \\
\hline \multirow{2}{*}{ Gender } & Male & 74 & 69 \\
\cline { 2 - 4 } & Female & 32 & 30 \\
\hline
\end{tabular}




\begin{tabular}{|l|l|c|c|}
\hline Category & Subcategory & $\begin{array}{c}\text { Number of } \\
\text { students }\end{array}$ & \% of students \\
\hline \multirow{4}{*}{ Ethnicity } & Other & 1 & 0.5 \\
\cline { 2 - 4 } & Prefer not to say & 1 & 0.5 \\
& White & 57 & 53 \\
\cline { 2 - 4 } & Asian (BAME)* & 37 & 34 \\
\cline { 2 - 4 } & Black (BAME) & 6 & 5 \\
\cline { 2 - 4 } & Arab (BAME) & 4 & 4 \\
\cline { 2 - 4 } & Other (BAME) & 4 & 4 \\
\hline \multirow{4}{*}{$\begin{array}{l}\text { Have lived abroad } \\
\text { Duration of living abroad } \\
\text { (43 students) }\end{array}$} & Yes & 43 & 40 \\
\hline \multirow{2}{*}{ Home country } & No & 65 & 60 \\
\cline { 2 - 4 } & $\leq 1$ year & 8 & 81 \\
\hline \multirow{2}{*}{$\begin{array}{l}\text { Speaking English as a first } \\
\text { language }\end{array}$} & $>1$ year & 35 & 66 \\
\cline { 2 - 4 } & Overseas & 37 & 70.4 \\
\cline { 2 - 4 } & Yes & 76 & 29.6 \\
\hline
\end{tabular}

*BAME: Black and Asian Minority Ethnic

Each year of the chemical engineering degree programme fosters cultural development of the students, since programmes contain one module dedicated to design, with initial teaching focused on the methodology of the design process whereby students work in permanent, crosscultural teams during a term or full year. Each of these modules complements the others by further developing earlier-learned skills and competencies, often within a more complex and more realistic context, whilst also introducing more advanced aspects of process engineering design and operations. By final year, students have the necessary competence in many areas, at which point teaching and support is concentrated on the newly-introduced topics, with areas of competence revised and refreshed as required. Furthermore, students have had major opportunities to explore what working in a cross-cultural team looks like, with support from allocated team mentors around teamworking good practice at that stage.

\subsection{Data Collection}

The Cultural Intelligence Survey (CQS), created and validated by Ang, Van Dyne et al. (2007), was used to measure individuals' cultural intelligence and was distributed in the form of hard copies to the 108 students who agreed to participate in this study during class time. Although the use of CQS is extremely scarce in engineering education research, it has been demonstrated to be a reliable instrument to measure aspects of cross-cultural competence across different 
educational areas such as business and management (Van Dyne, Ang et al. (2015)). A separate page was included to gather the demographic characteristics shown in Table 1. The CQS contains 20 items related to the four dimensions of cultural intelligence which are measured on a 7-point Likert-scale (' 1 ' meaning 'very strongly disagree' and ' 7 ' meaning 'very strongly agree'):

1) Metacognitive:

- MC1 I am conscious of the cultural knowledge I use when interacting with people with different cultural backgrounds

- MC2 I adjust my cultural knowledge as I interact with people from a culture that is unfamiliar to me

- MC3 I am conscious of the cultural knowledge I apply to cross-cultural interactions

- MC4 I check the accuracy of my cultural knowledge as I interact with people from different cultures

2) Cognitive:

- COG1 I know the legal and economic systems of other cultures

- COG2 I know the rules (e.g., vocabulary, grammar) of other languages

- COG3 I know cultural values and religious beliefs of other cultures

- COG4 I know the marriage systems of other cultures

- COG5 I know the arts and crafts of other cultures

- COG6 I know the rules for expressing nonverbal behaviours in other cultures

3) Motivational

- MOT1 I enjoy interacting with people from different cultures

- MOT2 I am confident that I can socialise with locals in a culture that is unfamiliar to me

- MOT3 I am sure I can deal with the stress of adjusting to a culture that is new to me

- MOT4 I enjoy living in cultures that are unfamiliar to me

- MOT5 I am confident that I can get accustomed to the shopping conditions in a different culture

4) Behavioural: 
- BEH1 I change my verbal behaviour (e.g., accent, tone) when a cross-cultural interaction requires it

- $\mathrm{BEH} 2$ I use pause and silence differently to suit different cross-cultural situations

- $\mathrm{BEH} 3$ I vary the rate of my speaking when a cross-cultural situation requires it

- BEH4 I change my nonverbal behaviour when a cross-cultural situation requires it

- BEH5 I alter my facial expressions when a cross-cultural interaction requires it

Taken together, these dimensions embrace the construct of cultural intelligence that describe the knowledge, skills, and attitudes needed to interact across cultures.

The CQS protocol was reviewed and approved by the corresponding ethics committee. All participants were informed of the survey by the author of this paper, D. Beneroso, and were told that the purpose of the study was to explore their cultural intelligence. They were further informed that the results would allow the researchers to understand the relationships between demographic characteristics and the four dimensions of cultural intelligence to further support their cross-cultural work in engineering teams. Students were given 30 minutes to complete the survey. All students signed consent forms as the first question on the survey, and they were allowed to remove their data from the study at a later date if they wished to do so. All participants answered all the questions.

\subsection{Data Analysis}

The descriptive and inferential statistical analyses were carried out using IBM SPSS Statistics version 24. Data were entered to IBM SPSS Statistics version 24 to conduct descriptive statistics. Frequency tables were produced with the purpose of presenting a descriptive statistics of the sample group, including means and standard deviations where appropriate (Tables 1-2).

Due to the categorical nature of data, non-parametric tests were used to compare the mean ranks from two or more data subcategories. Mann-Whitney $U$ test was used to compare dichotomous data, whereas Kruskal-Wallis test was used to compare trichotomous data. The Mann-Whitney $\mathrm{U}$ test is the non-parametric equivalent to the broadly used independent $t$-test and is the suitable analysis to compare differences that come from the same population when the dependent variable is ordinal (Leech, Barrett et al. (2005)). In essence, the Mann-Whitney $\mathrm{U}$ test compares the number of times a score from a population subcategory ranks higher than 
a score from a second subcategory. This involved pooling the CQS items scores from two subcategories into one combined sample and ranking such scores lowest to highest from 1 to $\mathrm{N}_{1}+\mathrm{N}_{2}$, where $\mathrm{N}_{1}$ and $\mathrm{N}_{2}$ represent the number of scores in the subcategory 1 and 2 , respectively, and calculating the sum of the ranks in each subcategory $\left(R_{1}\right.$ and $\left.R_{2}\right)$. The mean rank was calculated for each subcategory by dividing by the sum of ranks by the number of scores; i.e. $R_{1} / N_{1}$.and $R_{2} / N_{2}$, respectively, and the resulting values were subsequently used to infer which of the two subcategories presented a significantly higher score whenever the significance was corroborated by the U statistics (Cramer (2003)). To determine whether an observed difference between subcategories was significant, the Mann-Whitney U test compared the number of times a score from a population subcategory $\left(\mathrm{U}_{1}\right)$ ranked higher than a score from a second subcategory $\left(\mathrm{U}_{2}\right)$, as defined in Equations 1-2:

$$
\begin{aligned}
& U_{1}=N_{1} N_{2}+\frac{N_{1}\left(N_{1}+1\right)}{2}-R_{1} \quad(\text { Equation 1) } \\
& U_{2}=N_{1} N_{2}+\frac{N_{2}\left(N_{2}+1\right)}{2}-R_{2} \quad(\text { Equation 2) }
\end{aligned}
$$

The $\mathrm{U}$ statistics was computed as $U=\min \left(U_{1}, U_{2}\right)$ and the resulting value compared with the tabulated critical value of $U$ at a $95 \%$ level of confidence for the subcategory sizes $\left(N_{1}\right.$ and $\left.N_{2}\right)$. A statistical significance was established whenever the computed $U$ was lower than the critical value of $U$ at such $95 \%$ level of confidence (i.e. $p<0.05$ ). A more through explanation of the statistical methodologies for both tests can be found elsewhere (Leon (1998), Cramer (2003)).

Cronbach's $\alpha$ for the CQS in this study was estimated to be 0.88 , thus indicating a good reliability of the CQS scales to measure the intended CQS outcomes described in Section 2.2 Data Collection (Bryman (2016)), and ensuring internal consistency among the items in each dimension (Adamson and Prion (2013)).

\section{Results}

Table 2 presents the descriptive statistics of the CQ dimensions of the sample group, including averages on a scale of 1-7, standard deviations, and the minimum and maximum scored values for each of the CQ dimensions. Also, the overall CQ (average of the four CQ dimensions) is shown. Higher averages indicate higher cultural intelligence. The highest mean score of CQ dimensions was for motivational, whereas the cognitive CQ dimension scored the lowest. Minimum and maximum scores are given with a decimal figure since they account for the 
minimum and maximum averages of the CQS items, respectively, for each of the CQ dimensions.

Table 2 Descriptive statistics of the CQS and its dimensions

\begin{tabular}{|c|c|c|c|c|c|}
\hline $\begin{array}{c}\text { CQ and its } \\
\text { dimensions }\end{array}$ & $\begin{array}{c}\text { Number of } \\
\text { respondents }\end{array}$ & Mean & $\begin{array}{c}\text { Standard } \\
\text { Deviation }\end{array}$ & $\begin{array}{c}\text { Minimum } \\
\text { score }\end{array}$ & $\begin{array}{c}\text { Maximum } \\
\text { score }\end{array}$ \\
\hline Metacognitive CQ & 108 & 5.11 & 0.90 & 2.8 & 7.0 \\
\hline Cognitive CQ & 108 & 3.79 & 0.91 & 1.7 & 5.8 \\
\hline Motivational CQ & 108 & 5.30 & 1.04 & 2.4 & 7.0 \\
\hline Behavioural CQ & 108 & 4.63 & 1.15 & 1.2 & 7.0 \\
\hline Overall CQ & 108 & 4.64 & 0.72 & 2.4 & 6.4 \\
\hline
\end{tabular}

The inferential statistical analysis was carried out to establish the level of significance of each of the two demographic subcategories within a single CQ dimension, and this was performed for each of the four CQ dimensions and also for the overall CQ. Table 3 summarises the results of the inferential analysis, including the $p$-value and the calculated mean ranks following the Mann-Whitney $U$ tests. As an example, the subcategory 'BAME' within the demographic characteristic 'Ethnicity' has a higher mean rank in the 'Cognitive CQ' dimension, and therefore can be considered to have significantly higher cognitive CQ compared to the subcategory 'White'.

None of the subcategories was found to be significant across all the four CQ dimensions. Language was a significant subcategory for cognitive and motivational CQ, with students fluent in at least one foreign language other than English consistently having higher motivational and lower cognitive CQ, respectively. Home country was also a significant subcategory for both cognitive and motivational CQ, with overseas students having a higher cognitive CQ but a lower motivational CQ. Having lived abroad was a significant subcategory for cognitive and behavioural CQ, being inferred that students who had lived abroad showed higher cultural intelligence in those two facets. Also, students who had lived abroad for more than one year showed a significant higher cognitive intelligence. Ethnicity (White vs BAME students) was only a significant subcategory for cognitive CQ, with BAME students presenting higher levels of cognitive cultural intelligence. Finally, gender was found to be a significant subcategory only for behavioural CQ, with female students scoring significantly higher than male students. No significant subcategories were found for the metacognitive CQ dimension or the overall CQ. 
Table 3 Significant subcategories by CQ dimension. Significant when $p<0.05$

\begin{tabular}{|c|c|c|c|c|}
\hline \multirow{2}{*}{ CQ dimension } & $\begin{array}{c}\text { Significant } \\
\text { subcategories }\end{array}$ & \multicolumn{2}{|c|}{ Mean ranks for CQ dimensions } & $p$-value \\
\hline Metacognitive CQ & n/a & \multicolumn{2}{|c|}{ n/a } & n/a \\
\hline Cognitive CQ & Ethnicity & White: 47.14 & BAME: 62.73 & 0.010 \\
& Have lived abroad & Yes: 63.29 & No: 48.68 & 0.017 \\
& Duration of living abroad & >1 year: 24.79 & $<1$ year: 9.81 & 0.002 \\
& English as first language & Yes: 49.03 & No: 67.50 & 0.005 \\
& Home country & UK: 47.07 & Overseas: 68.76 & 0.001 \\
\hline Motivational CQ & English as first language & Yes: 61.93 & No: 36.84 & $<0.001$ \\
& Home country & UK: 59.41 & Overseas: 45.08 & 0.024 \\
\hline Behavioural CQ & Gender & Male: 49.28 & Female: 63.27 & 0.031 \\
& Have lived abroad & Yes: 63.99 & No: 48.22 & 0.010 \\
\hline Overall CQ & n/a & n/a & & n/a \\
\hline
\end{tabular}

Given the high proportion of Asian students in the cohort (34\%), an additional analysis was carried out using the Kruskal-Wallis test by considering three subcategories across the ethnicity category: White, Asian and Black Minority Ethnic (BME) students. No statistical significance was found for the metacognitive, behavioural or overall CQ domains across the three ethnic subcategories. Table 4 illustrates the fact that Asian and BME students had higher cognitive CQ than White students. On the other hand, BME students showed the highest motivational $\mathrm{CQ}$, whereas Asian students presented the lowest one.

Table 4 Kruskal-Wallis test for the 'Ethnicity' subcategories (White, Asian and BME)

\begin{tabular}{|c|c|c|c|c|}
\hline \multirow{2}{*}{ CQ dimension } & \multicolumn{3}{|c|}{$\begin{array}{c}\text { Mean ranks for CQ } \\
\text { dimensions }\end{array}$} & \multirow{2}{*}{$\boldsymbol{p}$-value } \\
\cline { 2 - 4 } & White & Asian & BME & \\
\hline Cognitive CQ & 47.14 & 62.82 & 62.42 & 0.035 \\
\hline Motivational CQ & 58.66 & 42.92 & 72.38 & 0.006 \\
\hline
\end{tabular}

\section{Discussion}

Although this is the first study that comprehensively characterises the CQ of final-year year undergraduate chemical engineering students to date, the overall average cultural intelligence of $4.64 \pm 0.72$ reported herein is very similar to those previously published on engineering education research; particularly, Mazzurco, Jesiek et al. (2012) reported similar average scores for their sample groups 'WPI IQP' (5.08 \pm 0.60$)$, 'China Abroad' (4.33 \pm 0.97$)$, 'ENGR103' $(4.92 \pm 0.72)$ and 'GEARE' (4.33 \pm 1.08$)$, and so did Jesiek (2013) for their 'ME Seminar' 


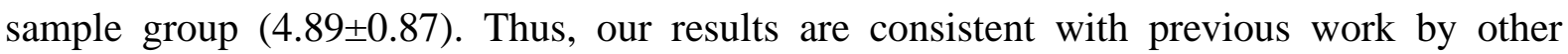
researchers in the same knowledge area (i.e., engineering). Table 5 summarises the main characteristics of such groups as an illustrative comparison with our sample group. In terms of sample size, academic level, ethnicity and gender, the 'ME Seminar' group is the most similar to our study group, whilst the demographics for the other groups, especially in terms of sample size, are more divergent. Nevertheless, despite these larger differences in sample size or ethnicities, the small observed differences in the overall CQ are virtually no significant as per our group's computed \pm 0.72 standard deviation.

Table 5 Demographic characteristics of sample groups reported in engineering education literature involving CQ characterisation of cohorts. Data extracted from Mazzurco, Jesiek et al. (2012) and Jesiek (2013)

\begin{tabular}{|c|c|c|c|c|c|c|}
\hline $\begin{array}{l}\text { Sample } \\
\text { group }\end{array}$ & WPI IQP & $\begin{array}{l}\text { China } \\
\text { Abroad }\end{array}$ & GEARE & ME Seminar & ENGR103 & This study \\
\hline Description & $\begin{array}{l}\text { Interdisciplinary } \\
\text { project-based } \\
\text { learning } \\
\text { programme (1-3 } \\
\text { terms), } \\
\text { including } \\
\text { project work } \\
\text { abroad }\end{array}$ & $\begin{array}{l}\text { Engineering } \\
\text { and computing } \\
\text { students } \\
\text { enrolled in a } \\
\text { one-semester } \\
\text { study abroad } \\
\text { programme in } \\
\text { China }\end{array}$ & $\begin{array}{l}\text { Comprehensive } \\
\text { study and } \\
\text { internship } \\
\text { abroad } \\
\text { programme }\end{array}$ & $\begin{array}{l}\text { Mechanical } \\
\text { engineering } \\
\text { students } \\
\text { enrolled in a } \\
\text { global } \\
\text { engineering } \\
\text { professional } \\
\text { seminar }\end{array}$ & $\begin{array}{l}\text { Global } \\
\text { engineering } \\
\text { learning } \\
\text { community } \\
\text { for students }\end{array}$ & $\begin{array}{l}\text { Chemical and } \\
\text { environmental } \\
\text { engineering students } \\
\text { enrolled in a design } \\
\text { and operations } \\
\text { team-based focused } \\
\text { programme }\end{array}$ \\
\hline $\begin{array}{l}\text { Number of } \\
\text { students }\end{array}$ & 22 & 28 & 17 & 142 & 21 & 108 \\
\hline $\begin{array}{l}\text { Academic } \\
\text { level }\end{array}$ & $\begin{array}{l}\text { Year } 3 \\
\text { undergraduates }\end{array}$ & $\begin{array}{l}\text { Year } 3 \text { and } 4 \\
\text { undergraduates }\end{array}$ & $\begin{array}{l}\text { Year } 3 \\
\text { undergraduates }\end{array}$ & $\begin{array}{l}\text { Mostly year } 2 \\
\text { and } \\
\text { undergraduates }\end{array}$ & $\begin{array}{l}\text { Year } 1 \\
\text { undergraduate } \\
\text { students }\end{array}$ & $\begin{array}{ll}\text { Year } & 3 \\
\text { undergraduates } & \end{array}$ \\
\hline $\begin{array}{l}\text { Gender } \\
\text { (male/female) }\end{array}$ & $50 \% / 50 \%$ & $82 \% / 18 \%$ & $65 \% / 35 \%$ & $79 \% / 21 \%$ & $67 \% / 33 \%$ & $70 \% / 30 \%$ \\
\hline Ethnicity & $\begin{array}{l}\text { BAME: } 19 \% \\
\text { White: } 81 \%\end{array}$ & $\begin{array}{l}\text { BAME: } 25 \% \\
\text { White: } 75 \%\end{array}$ & $\begin{array}{l}\text { BAME: } 29 \% \\
\text { White: } 71 \%\end{array}$ & $\begin{array}{l}\text { BAME: } 41 \% \\
\text { White: } 59 \%\end{array}$ & $\begin{array}{l}\text { BAME: } 67 \% \\
\text { White: } 33 \%\end{array}$ & $\begin{array}{l}\text { BAME: } 47 \% \\
\text { White: } 53 \%\end{array}$ \\
\hline $\begin{array}{l}\text { Have lived } \\
\text { abroad }\end{array}$ & $5 \%$ & $14 \%$ & $12 \%$ & $27 \%$ & $43 \%$ & $40 \%$ \\
\hline
\end{tabular}

Students for whom either their first language was English or the UK was their home country projected higher motivational CQ scores. These results suggest that the engineering students 
under those categories may have perceived themselves as comparatively more able to direct their attention and energy toward cultural differences in cross-cultural settings. Further insight into the CQS survey reveals that the item MOT2 I am confident that I can socialise with locals in a culture that is unfamiliar to me yielded the largest difference across the motivational intelligence dimension's items; overseas students felt, on average, $16 \%$ less confident to socialise in unfamiliar cultural settings than their fellow UK students. Moreover, students whose first language was not English also felt, on average, $8 \%$ less confident (Yu and Moskal (2019)). A number of studies have pointed out that motivational CQ is positively correlated to intercultural interaction and adjustment at the work place (Ang, Van Dyne et al. (2007), Subramaniam, Ramalu et al. (2011), Huff (2013), Guðmundsdóttir (2015)), and experiential learning interventions have been demonstrated to increase motivational CQ (MacNab (2012)). In the particular case of engineering education, Mazzurco, Jesiek et al. (2012) reported how the enrolment of a first-year engineering group in a global engineering learning community ('ENGR103' group in Table 5) resulted in a significantly higher motivational CQ (6.13 \pm 0.95$)$ as compared to the other sample groups without any academic training on cultural intelligence. Interestingly, the average motivational CQ for our students whose first language was not English but had been living in the UK for less than two years was lower (4.73) than for those who had lived in the UK more than two years (5.22), which suggests that the latter had more opportunities to enhance their desire to engage in intercultural exchanges, either in a social and/or an academic sphere; for instance, by means of cross-cultural experiential learning whilst working with fellow students.

Students who had previously lived abroad for part of their lives consistently presented higher behavioural CQ scores. This result suggests that the students under this category were more able to exhibit appropriate verbal and non-verbal actions when interacting with other students from different cultural backgrounds, and this is aligned with previous studies (Crowne (2008), Brancu, Munteanu et al. (2016)). For instance, Crowne (2008) found out that the number of countries visited for educational purposes had a positive influence towards individuals' behavioural cultural intelligence. Although a positive association between behavioural CQ and both task performance (i.e, completion of work obligations) and contextual performance (i.e., formation and growth of relationships with host country students or institutions) has been described (Rose, Ramalu et al. (2010)), students with high behavioural CQ seem to require the intervention of perceived efficiency when working in cross-cultural teams to foster knowledge sharing amongst fellow colleagues (Chen and Lin (2013)). Also female students consistently 
presented higher behavioural CQ compared to their male counterparts. However, literature evidence is very uneven in this regard, and consequently the question as to why gender is a significant subcategory for behavioural CQ remains unanswered (Khodadady and Ghahari (2011), Bücker and Korzilius (2015), Al-Dossary (2016), Brancu, Munteanu et al. (2016), Kamal Abdien and Jacob (2019), Tu, Zhang et al. (2020)). Further exploration into the CQS survey reveals that the items BEH1 I change my verbal behaviour (e.g., accent, tone) when a cross-cultural interaction requires it and BEH4 I change my nonverbal behaviour when a cross-cultural situation requires it stand for the largest and smallest difference in the behavioural intelligence dimension, respectively, between males and females. This is in agreement with Schwartz and Rubel (2005), who found that females credited more importance than males did to kindness and universalism values in a cross-cultural gender differences study involving 70 countries. Kindness values motivate people to preserve and improve the wellbeing of close others, and women's experiences, roles and their adaptive gain from caring for close others may make kindness values inherently more important to females (Valian (1999), Georgas, Berry et al. (2006), Davies and Shackelford (2008)). This inherently greater importance to females may also generalise to universalism values (i.e., understanding, appreciation, tolerance, and protection for the wellbeing of all people and for nature) because universalism values emerge through the extension of kindness values to the wider society, and therefore promoting changes in behaviours when cross-cultural interaction requires it (Schwartz (1992)). Another factor that can affect students' behaviour is self-efficacy. Selfefficacy can vary between genders and ethnicity which can affect how students perceive themselves as competent to interact or incompetent to avoid interactions (Buchanan and Selmon (2008)).

Ethnicity significantly influenced the level of cognitive CQ dimension, with BAME students seeming to have higher levels of knowledge and understanding of how cultures compare between each other acquired through educational and personal experiences (Brislin, Worthley et al. (2006)). Earley and Ang (2003) argued that to exhibit a high level of cognitive CQ, students should show flexibility to redesign and regulate one's self concept to novel cultural environments. Based on our results, it is highly likely that the BAME students have had to significantly modulate their insights into their social identity and role while working in crosscultural situations, with virtually no differences between Asian and BME students (Table 4). Although positive relationships have been found between higher cognitive CQ and knowledge sharing and interaction adjustment amongst team members in cross-cultural scenarios, this 
result indicates that being a BAME student is not inevitably a significant subcategory of the perceived global level of intercultural competence (Subramaniam, Ramalu et al. (2011)). Asian students reported a significantly lower motivational CQ, in line with previous findings from Peng, Van Dyne et al. (2015), this suggesting the importance of developing effective academic training to enhance students' motivational CQ, perhaps before they go abroad as part of their international exchange programmes. Overseas students had also significantly higher cognitive CQ scores, which is consistent with the findings from engineering cohorts reported by Mazzurco, Jesiek et al. (2012), this suggesting that overseas students had more opportunities to acquire cultural knowledge where an opportunity was available.

\subsection{Implications for practice}

The results reported herein provide the first data on the cultural intelligence of chemical engineering students. The high variability in significant demographic subcategories upon the four CQ dimensions suggests how important supporting other dimensions beyond cognitive $\mathrm{CQ}$, such as motivational or behavioural $\mathrm{CQ}$, is to help chemical engineering students in transitioning towards a global, cross-cultural work environment.

The first implication of this study is that it contributes to building up the extremely scarce body of research on $\mathrm{CQ}$ in an engineering education context, and particularly in a chemical engineering education context. A fundamental understanding of the interactions between demographic characteristics and the four dimensions of cultural intelligence is the first step towards the development of practice to minimise differences across the cohorts, and the drive behind a transition headed for a more global engineering educational strategy, where students can receive better support to efficiently deal with cross-cultural working tasks. Naturally, the CQS results reported herein cannot be interpreted to be exclusively course or programme related, but more likely to be a combination of the students' cultural capital and the social, working and school and university educational experiences accumulated during their lives. In the case of our reported chemical engineering cohort, the largest differences in cultural intelligence dimensions across categories that could be manipulated through practice (i.e., those except gender, ethnicity or home country) were found to be due to the students' first language ( $p<0.001$ for motivational CQ and $p=0.005$ for cognitive CQ), having lived abroad ( $p=0.010$ for behavioural CQ), and duration of living abroad ( $p=0.002$ for cognitive CQ). This primary knowledge is critical for educational leaders in their own context, as it constitutes the 
pillar supporting the rationale behind the implementation of any programme strategy or educational interventions to foster the cultural intelligence of their students. Higher education institutions are therefore encouraged to use the CQS protocol and outcomes to identify their rationale to best create and evaluate their own effective strategies to enhance cross-cultural diversity understanding, and subsequently provide their chemical engineering students enough opportunities to participate in decision making, task performance and adjustment processes when working in cross-cultural settings (Solomon and Steyn (2017)).

Amongst such strategies, the most common would consist of (a) implementing cross-cultural academic training that can help students to become more culturally intelligent through language, social science and engineering ethics courses or workshops (Mazzurco, Jesiek et al. (2012), Eisenberg, Lee et al. (2013), Murrugarra and Wallace (2014)); (b) running experiential learning activities and promoting the use of cross-cultural team-based active learning pedagogies, usually more suited to tackle with motivational and behavioural cultural intelligence shortcomings (Oladiran, Uziak et al. (2011), Rodriguez-Falcon, Hodzic et al. (2011), Mazzurco, Jesiek et al. (2012), Zou and Ko (2012), Kurpis and Hunter (2017), Najdanovic-Visak (2017)), or (c) promoting overseas exchanges that can improve both cognitive and behavioural CQ (Mazzurco, Jesiek et al. (2012), Brancu, Munteanu et al. (2016)). Apart from these formal interventions, institutions should also encourage informal in-campus strategies characterised by comfortable, casual contacts that could significantly influence the development of the students' CQ dimensions by immersing them into an iterative experiential learning process to gain cultural-specific knowledge, understand the opposed differences in cross-cultural scenarios and transform that knowledge into personal skills. Careful design of such activities by departments or faculties' student experience teams involving student associations or interest clubs, sports, games, and student hall mates where cross-culturalism were the driving force could be considered as examples of informal CQ empowerment practices (Lin and Shen (2019)). Moreover, the implementation of these initiatives could potentially serve as partial substitute to experiences abroad, especially for disadvantaged students who may have not had the opportunity of such educational or working experiences, whilst also lessening academic pressures and curricula's constraints on degree programmes.

\subsection{Limitations of the study}


This study opens up a new research area in chemical engineering education by providing, for the first time, empirical evidence of relating different demographics to the level of cultural intelligence of chemical engineering students in order to provide the knowledge base for educators, but it is not without its limitations.

The participants in the CQS survey were from a large, highly diverse final-year cohort from a single university which may have a limited representation of all universities in the United Kingdom in terms of diversity, albeit the findings also show some general similarities with other engineering higher education institutions. Data were collected using a self-report tool which may be inherently susceptible to social desirability bias, although Shannon and Begley (2008) showed that self- and peer-report following the CQS survey displayed a positive correlation. In this regard, Jesiek and Woo (2011) proposed the use of situation- and scenariobased strategies as complementary measures of global competence to reduce the inherent limitations to self-reporting based methodologies.

Another drawback is that the CQ literature in engineering education and cognate STEM areas is extremely scarce to make further thorough, consistent comparisons as to how the levels of cultural intelligence of chemical engineering students compare across different engineering areas and countries.

Moreover, there may be some limitations related to the inferential statistics outcomes from the demographic category 'have lived abroad', since some students may have lived abroad during their early childhood, this not necessarily influencing their cognitive and behavioural CQ dimensions as reported in Table 3.

As research continues, we aim at developing a conceptual model to help predict various workrelated outcomes in culturally-diverse academic activities, such as task performance, crosscultural adjustment, and decision-making. Further research into potential socio-economic limitations to developing students' cultural capital and CQ could also be investigated by the engineering education community in order to provide a greater robustness to our findings and our future aforementioned conceptual model. 


\section{References}

Adamson, K. A. and S. Prion, 2013. "Reliability: Measuring Internal Consistency Using Cronbach's $\alpha . "$ Clinical Simulation in Nursing 9(5): e179-e180.

Al-Momani, A.-L. and A. Atoum, 2016. "Cultural intelligence among Jordanian university students." International Journal of Education and Management Studies 6(1): 48.

Al-Dossary, S. A., 2016. "Psychometric properties of the cultural intelligence scale in a Saudi Arabian context." International Journal of Selection and Assessment 24(4): 305-311.

Alosaimi, N., M. Boyd and H. Boardman, 2019. "Cultural intelligence of MPharm undergraduates." International Journal of Pharmacy Practice 27(S2).

Ang, S., L. Van Dyne, C. Koh, K. Y. Ng, K. J. Templer, C. Tay and N. A. Chandrasekar, 2007. "Cultural intelligence: Its measurement and effects on cultural judgment and decision making, cultural adaptation and task performance." Management and organization review 3(3): 335371.

Báez, D., 2013. Cultural intelligence in foreign language classes.

Bennett, M. J., 1986. "A developmental approach to training for intercultural sensitivity." International journal of intercultural relations 10(2): 179-196.

Bhaskar, R., 2013. Philosophy and the Idea of Freedom, Routledge.

Bourdieu, P., 1986. "The forms of capital."

Brancu, L., V. Munteanu and I. Golet, 2016. "Understanding cultural intelligence factors among business students in Romania." Procedia-Social and Behavioral Sciences 221(7): 336. Brislin, R., R. Worthley and B. Macnab, 2006. "Cultural intelligence: Understanding behaviors that serve people's goals." Group \& Organization Management 31(1): 40-55.

Brown, J. S., A. Collins and P. Duguid, 1989. "Situated cognition and the culture of learning." Educational researcher 18(1): 32-42.

Brualdi Timmins, A. C., 1996. "Multiple intelligences: Gardner's theory." Practical Assessment, Research, and Evaluation 5(1): 10.

Bryman, A., 2016. Social research methods, Oxford university press.

Buchanan, T. and N. Selmon, 2008. "Race and gender differences in self-efficacy: Assessing the role of gender role attitudes and family background." Sex Roles 58(11-12): 822-836.

Bücker, J. J. and H. Korzilius, 2015. "Developing cultural intelligence: assessing the effect of the Ecotonos cultural simulation game for international business students." The International Journal of Human Resource Management 26(15): 1995-2014.

Chen, M. L. and C. P. Lin, 2013. "Assessing the effects of cultural intelligence on team knowledge sharing from a socio-cognitive perspective." Human Resource Management 52(5): 675-695.

Cramer, D., 2003. Fundamental statistics for social research: Step-by-step calculations and computer techniques using SPSS for Windows.

Cranmer, S., 2006. "Enhancing graduate employability: best intentions and mixed outcomes." Studies in Higher Education 31(2): 169-184.

Crowne, K. A., 2008. "What leads to cultural intelligence?" Business Horizons 51(5): 391-399. Crowne, K. A., 2013. "Cultural exposure, emotional intelligence, and cultural intelligence: An exploratory study." International Journal of Cross Cultural Management 13(1): 5-22.

Davies, A. P. and T. K. Shackelford, 2008. "Two human natures: How men and women evolved different psychologies." Foundations of evolutionary psychology. Lawrence Erlbaum, New York: 261-280.

Davis, K. and D. B. Knight, 2018. "Impact of a global engineering course on student cultural intelligence and cross-cultural communication." Journal of International Engineering Education 1(1): 4. 
Del Vitto, C., 2008. "Cross-Cultural "Soft Skills" and the Global Engineer: Corporate Best Practices and Trainer Methodologies." Online Journal for Global Engineering Education 3.

Earley, P. C., 2002. "Redefining interactions across cultures and organizations: Moving forward with cultural intelligence." Research in organizational behavior 24: 271-299.

Earley, P. C. and S. Ang, 2003. Cultural intelligence: Individual interactions across cultures, Stanford University Press.

Eisenberg, J., H.-J. Lee, F. Brück, B. Brenner, M.-T. Claes, J. Mironski and R. Bell, 2013. "Can business schools make students culturally competent? Effects of cross-cultural management courses on cultural intelligence." Academy of Management Learning \& Education 12(4): 603621.

Etzkowitz, H., C. Kemelgor and B. Uzzi, 2000. Athena unbound: The advancement of women in science and technology, Cambridge University Press.

AuthoR, 2009. Cultural intelligence: Engineering success for a flat world. American Society for Engineering Education, American Society for Engineering Education.

Georgas, J., J. W. Berry, F. J. Van de Vijver, Ç. Kagitçibasi and Y. H. Poortinga, 2006. Families across cultures: A 30-nation psychological study, Cambridge University Press.

Goh, M., 2012. "Teaching with cultural intelligence: developing multiculturally educated and globally engaged citizens." Asia Pacific Journal of Education 32(4): 395-415.

Graham, R., 2018. "The global state of the art in engineering education." Massachusetts Institute of Technology (MIT) Report, Massachusetts, USA.

Guðmundsdóttir, S., 2015. "Nordic expatriates in the US: The relationship between cultural intelligence and adjustment." International Journal of Intercultural Relations 47: 175-186.

Huff, K. C., 2013. "Language, cultural intelligence and expatriate success." Management Research Review.

Jesiek, B. K., 2013. "Global Engineering Design Symposium: Engaging the Sociocultural Dimen-sions of Engineering Problem Solving." 23: 1.

AuthoR, 2011. Realistic assessment for realistic instruction: Situational assessment strategies for engineering education and practice. Proceedings of the 2011 SEFI Annual Conference, Lisbon, Portugal.

Kamal Abdien, M. and M. Jacob, 2019. "Cross-cultural training and cultural intelligence of hospitality students: a case study in Egypt and Spain." Journal of Teaching in Travel \& Tourism 19(3): 191-215.

Khodadady, E. and S. Ghahari, 2011. "Validation of the Persian cultural intelligence scale and exploring its relationship with gender, education, travelling abroad and place of living." Global Journal of Human Social Science 11(7): 65-75.

King, P. M. and M. B. Baxter Magolda, 2005. "A developmental model of intercultural maturity." Journal of college student development 46(6): 571-592.

Kitchenham, A., 2002. "Viv la difference: Gender, motivation and achievement." School libraries in Canada 22(2): 34.

Kurpis, L. H. and J. Hunter, 2017. "Developing students' cultural intelligence through an experiential learning activity: A cross-cultural consumer behavior interview." Journal of Marketing Education 39(1): 30-46.

Leech, N. L., K. C. Barrett and G. A. Morgan, 2005. SPSS for intermediate statistics: Use and interpretation, Psychology Press.

Leon, A. C., 1998. 3.12 - Descriptive and Inferential Statistics. Comprehensive Clinical Psychology. A. S. Bellack and M. Hersen. Oxford, Pergamon: 243-285.

Lin, X. and G. Q. Shen, 2019. "How formal and informal intercultural contacts in universities influence students' cultural intelligence?" Asia Pacific Education Review: 1-15. 
Lucena, J. and J. Schneider, 2008. "Engineers, development, and engineering education: From national to sustainable community development." European Journal of Engineering Education 33(3): 247-257.

MacNab, B. R., 2012. "An experiential approach to cultural intelligence education." Journal of Management Education 36(1): 66-94.

Mazzurco, A., B. Jesiek and K. D. Ramane, 2012. "Are engineering students culturally intelligent?: Preliminary results from a multiple group study." ASEE Annual Conference and Exposition, Conference Proceedings.

AuthoR, 2014. Cross-cultural and cross-national impact of ethics education on engineering students. 2014 IEEE international symposium on ethics in science, technology and engineering, IEEE.

Najdanovic-Visak, V., 2017. "Team-based learning for first year engineering students." Education for Chemical Engineers 18: 26-34.

Ng, K.-Y., M. L. Tan, S. Ang, I. A. Burton and J. Spender, 2011. "Culture capital and cosmopolitan human capital: The impact of global mindset and organizational routines on developing cultural intelligence and international experiences in organizations." The Oxford handbook of human capital: 96-119.

Oladiran, M., J. Uziak, M. Eisenberg and C. Scheffer, 2011. "Global engineering teams-a programme promoting teamwork in engineering design and manufacturing." European Journal of Engineering Education 36(2): 173-186.

Ott, D. L. and S. Michailova, 2018. "Cultural intelligence: A review and new research avenues." International Journal of Management Reviews 20(1): 99-119.

Paige, R. M. and J. N. Martin, 1996. "Ethics in intercultural training." Handbook of intercultural training 2: 35-60.

Peng, A. C., L. Van Dyne and K. Oh, 2015. "The influence of motivational cultural intelligence on cultural effectiveness based on study abroad: The moderating role of participant's cultural identity." Journal of Management Education 39(5): 572-596.

Rodriguez-Falcon, E., A. Hodzic and A. Symington, 2011. "Learning from each other: engaging engineering students through their cultural capital." engineering education 6(2): 2938.

Rose, R. C., S. S. Ramalu, J. Uli and N. Kumar, 2010. "Expatriate performance in international assignments: The role of cultural intelligence as dynamic intercultural competency." International Journal of Business and Management 5(8): 76.

Schwartz, S. H., 1992. "Universals in the content and structure of values: Theoretical advances and empirical tests in 20 countries." Advances in experimental social psychology 25(1): 1-65. Schwartz, S. H. and T. Rubel, 2005. "Sex differences in value priorities: Cross-cultural and multimethod studies." Journal of personality and social psychology 89(6): 1010.

Shannon, L. M. and T. M. Begley, 2008. "Antecedents of the four-factor model of cultural intelligence." Handbook of cultural intelligence: Theory, measurement, and applications: 4155.

Solomon, A. and R. Steyn, 2017. "Exploring cultural intelligence truths: A systematic review." SA Journal of Human Resource Management 15(1): 1-11.

Stolle-McAllister, K., 2011. "The Case for Summer Bridge: Building Social and Cultural Capital for Talented Black STEM Students." Science Educator 20(2): 12-22.

Subramaniam, A., I. Ramalu, C. C. Wei and R. C. Rose, 2011. "The effects of cultural intelligence on cross-cultural adjustment and job performance amongst expatriates in Malaysia." International Journal of Business and Social Science 2(9).

Tu, J.-C., X.-Y. Zhang and S.-P. Chiu, 2020. "Assessing the Impact of Cultural Intelligence on Sustainable Career Competitive Advantage for Students in College of Design." Sustainability 12(1): 10 . 
Tymon, A., 2013. "The student perspective on employability." Studies in higher education 38(6): 841-856.

Valian, V., 1999. Why so slow?: The advancement of women, MIT press.

Van Dyne, L., S. Ang and C. Koh, 2015. Development and validation of the CQS: The cultural intelligence scale. Handbook of cultural intelligence, Routledge: 34-56.

Van Dyne, L., S. Ang and D. Livermore, 2010. "Cultural intelligence: A pathway for leading in a rapidly globalizing world." Leading across differences: 131-138.

Wood, E. D. and H. Y. St. Peters, 2014. "Short-term cross-cultural study tours: impact on cultural intelligence." The International Journal of Human Resource Management 25(4): 558570.

Yu, Y. and M. Moskal, 2019. "Missing intercultural engagements in the university experiences of Chinese international students in the UK." Compare: A Journal of Comparative and International Education 49(4): 654-671.

Zou, T. X. P. and E. I. Ko, 2012. "Teamwork development across the curriculum for chemical engineering students in Hong Kong: Processes, outcomes and lessons learned." Education for Chemical Engineers 7(3): 105-117. 